\title{
Diagnostic Ultrasound Safety: 3. Heating Effect on Animal Fetus in Biology
}

Kazuo Maeda*

Department of Obstetrics and Gynecology (Emeritus), Tottori University Medical School, Yonago, Japan

\begin{abstract}
Animal fetus develops head and neck malformations after direct exposure to high temperature for long time in biological experiments. Since ultrasound develops heat by the absorption of ultrasound to the tissue, and the temperature elevation is parallel to tempolarly averaged ultrasound intensity, the thermal ultrasound bioeffect is discussed refering the results of animal fetus heating experiments.
\end{abstract}

There are various methods to physically measure the ultrasound intensity, e.g. hydrophone, pressure balance, steel ball displacement, and so on. These techniques measure ultrasound intensity, while their relation to the bioeffect should be estimated by any biological changes. Since the tissue exposed to ultrasound absorbs ultrasound to rise the tissue temperature, while the effect of temperature rise on animal fetal changes were experimented and the massive results were already reported in biology. Therefore, ultrasound bioeffect is estimated by the temperature rise caused by ultrasound absorption by the exposed tissue. The method is unique, because biologically teratogenic effect of fetal heating to develop animal fetal head and neck anomaly was quantitatively determined by the temperature rise and exposure time, and ultrasound exposureis quantified by tissue temperature rise due to ultrasound absorption. Both parameters are quantitatively compared. High temperature exposure short time and relatively low temperature rise for long exposure both develop animal fetal anomaly. The results were accumulated in experimental biology, and it is possibleto estimate ultrasound thermal bioeffect directly by the temperature rise of ultrasound absorbed tissue. There were experimental data of the animal fetuses directly exposed to high temperature in biological experiments. Fetal animal developed head and neck abnormalities after the exposure to high temperature short time, and long exposure to relatively low temperature. National council on Radiation Protection and Measurements (NCRP) reported the summary of biological experiments on the effect ofexposure of animal fetus to heat [1], where the anomalies develop linearly parallel to temperature rise above physiological body temperature. The time to develop anomaly in animal fetus is short in high temperature rise and long to low temperature rise, e.g. $1,000 \mathrm{~min}$ in $38^{\circ} \mathrm{C}$ and $1 \mathrm{~min}$ in $43^{\circ} \mathrm{C}$. The time is reversely parallel to the temperature (Figure 1) [1].

Thus, the relation of temperature rise and biological effect in animal experimentwas applied to estimate the thermal bioeffect of diagnostic ultrasound as discussed later in this series of diagnostic ultrasound safety.

\section{References}

1. National council on radiation protection and measurements (NCRP) (1992) Exposure Criteria for Medical Diagnostic Ultrasound: I. Criteria based on Thermal Mechanisms. NCRP Report No. 113, Bethesda.

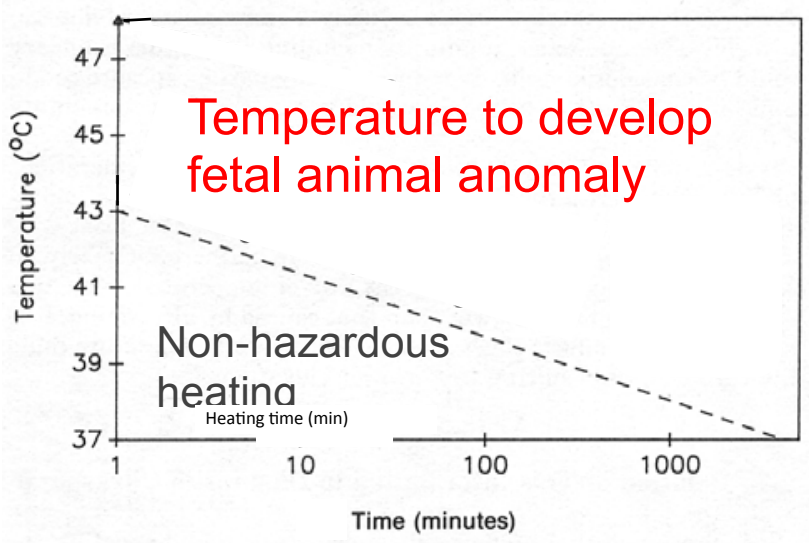

Figure 1: High temperature and exposure time to develop anomaly in animal fetus.

\begin{abstract}
*Corresponding author: Kazuo Maeda, Department of Obstetrics and Gynecology (Emeritus), Tottori University Medical School, Yonago, Japan, 3-125, Nadamachi, Yonago, Tottoriken, 6830835, Japan, Tel: 81-859-22-6856; Fax: 81-859-22-6856; E-mail: maeda@mocha.ocn.ne.jp
\end{abstract}

Received January 07, 2013; Accepted January 23, 2014; Published January 29 2014

Citation: Maeda K (2014) Diagnostic Ultrasound Safety: 3. Heating Effect on Animal Fetus in Biology. J Health Med Informat 5: 146. doi:10.4172/21577420.1000146

Copyright: (c) 2014 Maeda K. This is an open-access article distributed under the terms of the Creative Commons Attribution License, which permits unrestricted use, distribution, and reproduction in any medium, provided the original author and source are credited. 